\title{
Regulating the new information intermediaries as gatekeepers of information diversity
}

\author{
Helberger, Natali ; Kleinen-von Könisglöw, Katharina ; van der Noll, Rob
}

\begin{abstract}
Purpose - The purposes of this paper are to deal with the questions: because search engines, social networks and app-stores are often referred to as gatekeepers to diverse information access, what is the evidence to substantiate these gatekeeper concerns, and to what extent are existing regulatory solutions to control gatekeeper control suitable at all to address new diversity concerns? It will also map the different gatekeeper concerns about media diversity as evidenced in existing research before the background of network gatekeeping theory critically analyses some of the currently discussed regulatory approaches and develops the contours of a more user-centric approach towards approaching gatekeeper control and media diversity. Design/methodology/approach - This is a conceptual research work based on desk research into the relevant and communications science, economic and legal academic literature and the relevant laws and public policy documents. Based on the existing evidence as well as on applying the insights from network gatekeeping theory, this paper then critically reviews the existing legal/policy discourse and identifies elements for an alternative approach. Findings - This paper finds that when looking at search engines, social networks and app stores, many concerns about the influence of the new information intermediaries on media diversity have not so much their source in the control over critical resources or access to information, as the traditional gatekeepers do. Instead, the real bottleneck is access to the user, and the way the relationship between social network, search engine or app platforms and users is given form. Based on this observation, the paper concludes that regulatory initiatives in this area would need to pay more attention to the dynamic relationship between gatekeeper and gated. Research limitations/implications - Because this is a conceptual piece based on desk-research, meaning that our assumptions and conclusions have not been validated by own empirical research. Also, although the authors have conducted to their best knowledge the literature review as broad and as concise as possible, seeing the breadth of the issue and the diversity of research outlets, it cannot be excluded that we have overlooked one or the other publication. Practical implications This paper makes a number of very concrete suggestions of how to approach potential challenges from the new information intermediaries to media diversity. Social implications - The societal implications of search engines, social networks and app stores for media diversity cannot be overestimated. And yet, it is the position of users, and their exposure to diverse information that is often neglected in the current dialogue. By drawing attention to the dynamic relationship between gatekeeper and gated, this paper highlights the importance of this relationship for diverse exposure to information. Originality/value - While there is currently much discussion about the possible challenges from search engines, social networks and app-stores for media diversity, a comprehensive overview in the scholarly literature on the evidence that actually exists is still lacking. And while most of the regulatory solutions still depart from a more pre-networked, static understanding of "gatekeeper", we develop our analysis on the basis for a more dynamic approach that takes into account the fluid and interactive relationship between the roles of "gatekeepers" and "gated". Seen from this perspective, the regulatory solutions discussed so far appear in a very different light.
\end{abstract}

DOI: https://doi.org/10.1108/info-05-2015-0034 
ZORA URL: https://doi.org/10.5167/uzh-116273

Journal Article

Accepted Version

Originally published at:

Helberger, Natali; Kleinen-von Könisglöw, Katharina; van der Noll, Rob (2015). Regulating the new information intermediaries as gatekeepers of information diversity. Info (Bingley) - The journal of policy, regulation and strategy for telecommunications, information and media, 17(6):50-71.

DOI: https://doi.org/10.1108/info-05-2015-0034 


\section{Regulating the new information intermediaries as gatekeepers of information diversity}

Prof. Dr. Natali Helberger, ${ }^{1}$ Prof. Dr. Katharina Kleinen-Von Königslöw, ${ }^{2}$ Dr. Rob van der Noll ${ }^{3}$

\section{Introduction}

Feeding debates, bringing news and exposing people to relevant content is not any longer a privilege of the traditional media. New players in the competition for the attention of users have entered the scene, including search engines, social networks and e-commerce platforms. The recent announcement of Facebook to cooperate with news agencies and publishers to offer their content directly on Facebook is just another piece of evidence to the growing importance of new information intermediaries for access to, and consumption of media content. The resulting concerns are various, and range from economic and competition concerns to concerns related to public media policy and the kind of information society we want to live in. It is the latter aspect that this article will concentrate on, and here in particular concerns about information diversity.

When policy makers and academics speak about Facebook, Google and Co., and their influence on media diversity, the notion of "gatekeeper" and "bottleneck" is often not far away. The qualification of Google or any other information intermediary as gatekeeper is not only a matter of rhetoric. From the legal and public policy point of view, there is a long tradition of disciplining gatekeeper control, also and particularly if such control threatens the realization of important public policy goals, such as media diversity and competition on the market place of ideas. Many of the traditional tools to safeguard media diversity and to discipline gatekeeper control - such as access obligations, due prominence and media ownership rules, as well as diversity requirements - have also been brought forward in one way or other, in the ongoing debates about the new information intermediaries. But how much sense does it make to apply the existing tools to new challenges, and what exactly are the challenges for media diversity from the new information intermediaries?

The objectives of this article are three-fold. First, the article will map the different gatekeeper concerns about media diversity that are associated with the new information intermediaries 'gatekeeper' concepts, and to what extent these concerns are actually backed up by empirical research. This will help to assess the urgency and adequacy of applying one or some of the suggested regulatory solutions. Secondly, the article will provide an overview of the regulatory options to safeguard media pluralism and control gatekeeper control so far, and explain why most of them are unlikely to be particularly effective in context

\footnotetext{
${ }^{1}$ Institute for Information Law, University of Amsterdam.

2 University of Zurich.

${ }^{3}$ SEO Economic Research, Amsterdam.
} 
with the new information intermediaries. More specifically, the article will demonstrate why when looking at search engines, social networks, and app stores, the traditional gatekeeper definition seems no longer useful. Following Barzilai (2008) we shall draw inspiration from management and information science, where gatekeepers are seen more as intermediaries of information, who gather and disseminate information within organizations, communities or professional contexts, usually with strong links between intermediaries and the members of their networks. In today's digital information environment, this understanding of gatekeeping seems more appropriate, as the roles of "gatekeepers" and "gated" have become more fluid and interchangeable, for example in processes of peer recommendations.

Third, and based on the analysis of the existing empirical evidence and the insights from network gatekeeping theory, this article will argue that many concerns about the influence of the new information intermediaries have not so much their source in the control over critical resources or access to information, as the traditional gatekeepers do. Instead, the real bottleneck is access to the user, and the way the relationship between social network, search engine or app platforms and users is given form. Based on this observation, the article concludes by suggesting an alternative or complementary approach for countering possible pluralism concerns with the new information intermediaries.

\section{New information intermediaries as gatekeepers, and concerns about media diversity}

\subsection{Media diversity as a public policy goal, and its different dimensions}

The realization of media diversity is considered a central goal of national and European media policies, and necessary premise for the exercise of people's fundamental right to freedom of expression, which "will be fully satisfied only if each person is given the possibility to form his or her opinion from diverse sources of information" (Council of Europe, 1999). This is also true for a converging media environment, where the supply, distribution and consumption of diverse content is not limited to the traditional media, but where both old and new players explore the potential of new communications channels, such as the internet or mobile applications (European Commission, 2013; European Commission, 2010; High Level Expert Group on Media Freedom and Pluralism, 2013; Council of Europe, 2007; Council of Europe, 2008; Council of Europe, 2012; Ofcom, 2012; Neuberger \& Lobgis, 2010; Napoli \& Karppinen, 2013; European Commission, 2007).

For the time being, media diversity is still primarily conceptualized as diversity of supply and output (different speakers, different outputs), at least in the public policy debate. ${ }^{4}$ And while it is very possible that search engines, social networks and app platforms affect the diversity of players and the way they compete at the 'market place of ideas' (see sections 2.3 and 2.4), this is only half of the story. New information intermediaries can not only affect competition at the market place of ideas, as the common

\footnotetext{
${ }^{4}$ See already the definition of the Council of Europe, according to which "pluralism is about diversity in the media that is made available to the public, which does not always coincide with what is actually consumed" (Council of Europe, 1999).
} 
metaphor to describe media pluralism, but also if, and to what extent that competition actually results in diverse exposure of users to media contents. By influencing search and consumption behaviour of users through filtering, targeted recommendations, social search, etc. the new information intermediaries not only affect diversity of supply, but also diversity of exposure (Napoli, 1999). 'Exposure diversity' thus looks at the audience dimension of media diversity, and the question to what extent the diversity of content and supply actually results in a (more) diverse program consumption. The aspect of exposure diversity is particularly critical for assessing possible benefits and threats brought about by new information intermediaries, such as search engines and social networks.

\subsection{Different types of gatekeepers, and why the distinction matters in media law and policy}

Common to most concerns about the influence of search engines, social networks and app stores on media diversity are concerns about their alleged gatekeeper position, and the level of power and influence they can exercise about the different phases of media supply, distribution and consumption (Schulz, et al., 2011; Neuberger \& Lobgis, 2010).

Traditionally, in the scholarly discourse two major types of gatekeepers can be roughly distinguished: the gatekeeper as controller of access to information and the gatekeeper who has a facilitating role through its control of critical intermediary resources or services that are necessary to link users and content, to intermediate between the different players in the information chain, to produce, transport and distribute content, etc. (compare (Laidlaw, 2010)). An example of the former is the editor who by power of his position, authority and knowledge selects the types, format and order of contents that are ultimately presented to the audience. An example of the latter is the ISP or operators of a cable network channel or a pay-TV platform - resources that are needed to transmit contents between sender and receiver. The distinction does matter because the different types of gatekeepers are associated with different types of influences on media diversity (Schulz, et al., 2011) (see section 2.3 and 2.4). What is more, for the different types of gatekeepers, different types of regulatory tools and mechanisms have been developed to control the influence and undesirable side effects for the realization of public policy objectives, such as media diversity.

Regarding editorial control over access to and selection of information, the associated types of direct and indirect editorial influences are subject to media law's requirements for editors of media content with the goal to make sure that direct editorial influences are not in conflict with established public policy objectives, such as the protection of minors, the representation of European content, or media diversity. Importantly, media law distinguishes between different levels of societal responsibility: public broadcasters have traditionally played a rather prominent role of public interest intermediary, and as such face heavy regulatory burdens with regards to their general accessibility, quality and diversity of their programming, but also the level of external commercial influences that are allowed. To the contrary, commercial broadcasting and on demand services are subject to a lesser degree of institutionalized social responsibility, and thus also to lesser legal requirements regarding, inter alia, the diversity of their programming. In addition, the media, and the press in particular, are also subject to ethical principles and self-regulation, with media diversity being only one out of many (ethical) requirements. 
To the contrary, gatekeepers as controllers of critical facilities are subject to general and sector-specific competition law, most prominently in the area of communications regulation. Because of its character as (sector-specific) competition law, communication law's overall objectives are less to foster public debate or media diversity, and more to prevent that control over critical resources amounts to distortions of economic competition. Typically, these are means of access obligations and control of market or opinion power. A somewhat odd, intermediary position is occupied by the rules about Electronic Program Guides, and the resulting provisions on due prominence, which are, arguably, one of the first regulatory attempts to regulate search. Though positioned in sector-specific competition law (communications law), they also clearly include content-related aspects, which some member states have transposed in their national media laws.

The example of EPG regulation already suggests how difficult the theoretical distinction between editorlike gatekeepers and more structural gatekeepers that control access over essential facilities is to maintain in a converging environment. Insofar, it is also little surprising that with regards to search engines, social networks and app platforms, both types of gatekeeper regulations are being discussed. Search engines, app platforms and social networks combine characteristics of both types of gatekeeper conceptualizations. A search engine, for example, has been defines as "an information retrieval system for the public networked information environment" (Van Hoboken, 2012, p. 33). As such, they provide a central platform for both, information providers and information seekers, and act as 'central brokers in many of the partly overlapping value chains in the networked online information environment' (Van Hoboken, 2012, p. 39). At the same time, they have an important role in selecting and ordering information, thereby organizing information flows and access to information, which is also why in the public policy discourse, they are associated with editor-like functions (Foster, 2012). Regarding social networks, Van Dijk described e.g. Facebook as "the software interface to channel communicative traffic between people" (Van Dijk, 2012), and hence a facility to link and connect people. Facebook also exercises control regarding the information (not) presented, e.g. in its news stream, and the recent Facebook experiment made very clear that the platform can take a rather active interest in even editing and modifying content on personal profiles. App platforms, finally, provide a digital market place for informational applications, but again, through the way in which information products are presented (e.g. personalized recommendations, prioritization) or excluded from access to the platform, they also have an important role in controlling access to information (Jullien, 2005).

But before investigating which kind of regulatory solutions have been suggested and whether they actually respond to the challenges posed by the new information intermediaries for media diversity (section 3.1), we will first provide some insight of what these challenges actually are, or what we (do not yet) know about them.

\subsection{Search engines, social networks and app platforms as editors}

The following section will provide an in-depth analysis, based on literature review, to what extent the different concerns about the different forms of editorial or structural influences have been advanced, and not less importantly whether they are relevant in practice, as shown by empirical research. 


\subsubsection{Direct-editorial influences}

Editorial control refers to the control of the content, style, format and structure of the information offered or distributed which then may affect the public and political agenda. Individuals or institutions with editorial control do not necessarily have the intention to influence politics: Whether journalists for example consider political influence as part of their professional role depends strongly on the overall journalistic culture of the country and on the specific newsroom (Donsbach \& Patterson, 2004). However, they all share an awareness that the conducted editorial activities may have an impact on society and politics. Therefore ethical considerations such as a perceived responsibility to inform citizens, to promote media diversity and diversity as well as to comply with any legislative framework applying to media companies play an important role in traditional news outlets. News selection is closely monitored by both formal (editing process) and informal (professional norms) control structures.

Turning to the new information intermediaries, these mostly lack the self-understanding as news providing media outlets, the corresponding editorial mission and hence also these internal control structures. Their employees do not have journalistic training which might promote an adherence to journalistic norms and an awareness of the potential political or societal impact of editorial decisions. This does not take away, however, that even though they do not publish their own news, search engines, social media and app platforms routinely take editorial decisions by blocking access to offensive or illegal content in order to comply with local legislation, local sensibilities or in response to requests of concerned parties. Given the enormous amounts of data, some of them apply automatic filtering mechanisms, while others rely on a large staff of administrators to review complaints of offensive content (for an overview (Gomez Marmol, et al., 2014), a very labour intensive process which is also susceptible to manipulation. Here, we still lack systematic analyses how this form of content censorships affects the diversity of supply. Some of the new intermediaries, such as the search engine Google, provide reports on received requests for content removal (Google, 2013). These reveal quite a number of attempts to suppress politically adverse content, even for democratic countries; but the full extent of the resulting bias is difficult to assess.

\subsubsection{Indirect-editorial influences:}

Even when information intermediaries exert no direct influence or involvement in the production, aggregation and (non-) distribution of (information) content, they may have an indirect influence in particularly on the diversity of exposure by affecting the findability of contents, the (not neutral) ordering and prioritization of existing contents and the management and direction of user attention as scarce resource, as well as influencing the choices users make. This can be in form of offering basic search functionality, but also algorithmic or collaborative filtering and the issuing of personalized search results and recommendations (Schulz, et al., 2011; European Commission, 2013; Council of Europe, 2012; High Level Expert Group on Media Freedom and Pluralism, 2013).

The control over the diversity of opinions in the presented content has thus largely been handed to the audience as a whole, to the individual user, but most importantly to the engineers constructing the website's architecture and personalization algorithms. Whether this should already be in itself is sufficient to be considered "editorial control" is a question that academic research has so far failed to address adequately. 5 From the few existing studies on the motivations and self-perceptions of search engine

\footnotetext{
${ }^{5}$ There is some debate on the neutrality of search engines (Vogl \& Barrett, 2010), but no systematic assessment of editorial policies of the new information intermediaries themselves.
} 
engineers (Van Couvering, 2007), or providers of social networks ( (Busch \& Sheperd, 2014) it becomes clear that they place little importance on public responsibility or diversity - even though they may use social responsibility as a marketing tool.

The economic literature seems to confirm this conclusion. Polo (2007) analyses the incentives for both external and internal diversity, drawing on the existing literature. The main insights from this theoretical literature are as follows. First, the principle of 'Maximum Differentiation' holds that media companies facing a public of viewers characterised by heterogeneous taste for content and a disutility from advertising will choose maximally differentiated content vis-à-vis each other (Gabszewicz et al. 1999). It is important to note that the differentiation of content will occur for the dimensions that the public cares about. Thus, if the public is heterogeneous in terms of e.g. entertainment and not in terms of their interest in politics, Maximum Differentiation entails that media companies differentiate themselves in entertainment but converge to a median or central political positioning. Thus when there are multiple dimensions of content, firms will maximally differentiate on the dimensions that are more important for consumers, while converging to minimum differentiation on the dimensions that are less important to consumers (Irmen \& Thisse, 1998). Second, when investment in quality is taken into account the prediction is different. Improving quality results in fixed costs. For the case that the distribution of tastes is very concentrated on a limited number of varieties, there is little scope for differentiation, due to the fact that firms need to compete intensively on the quality they provide for the singular preferred variety (Motta \& Polo, 2001). Thus, the authors conclude, the concentration of firms caused by the fixed costs spent on quality, combined with the public's relatively undifferentiated tastes, weakens the provision of external diversity by the market. For example comparative studies on the political information supply provided by television broadcasters conclude that increased market competition leads to less news and current affairs programming, in other words less quality programming overall (Esser, et al., 2012).

Similarly, the business model of a search engine is to attract users in order to gain income from advertisements (Taylor, 2013). According to Frijters and Velamuri (2010) this continues to be dominant model also for news markets, despite digitisation and the rise of the internet. The product a search engine delivers, the search results, must be attractive for consumers. Therefore, search engines invest in improving the quality of the organic search results (Varian, 2008) (Taylor, 2013). According to some findings in the literature and Google's statements, they also compete on quality: 'competition is a click away' (Gandal, 2001). Hence, search engines have an incentive to invest in quality in order to maintain and improve attractiveness for users. The open question is however whether quality implies diversity. Presumably, search algorithms rank websites on the basis of popularity (one of the algorithms used by Google is PageRank and this algorithm favours websites that receive a higher number of referrals). There could thus be a tension between quality and diversity: consumers prefer a ranking based on popularity which implies convergence of search results to a limited subset of frequently used websites. The same can be said about social network sites where the urge to follow others may reduce diversity.

Overall Increase in possibilities of choice, but again: bias towards more popular contents by established news brands 
From the perspective of media users, the new information intermediaries all represent an increase in the availability and accessibility of information. Search engines provide them with long lists of sources they would have had difficulties to find on their own. The overall variety on these lists is great, often including smaller, lesser-known sources, from all corners of the globe, which may lead to a diversification of the news supply: For example Thurman (2007) can show that today Americans make up a third of the audience of British news websites due to their visibility on international news aggregators such as Google News. However, this phenomenon is limited to popular topics and websites. More specialized media outlets, or those originating in smaller (online-)markets, are less likely to achieve good rankings in the lists of search engines and news aggregators and thus less likely to profit from new transnational reader flows. Because, as already mentioned, in general the ranking algorithms of both search engines and news aggregators strongly favours very popular sites, this leads to a high degree of concentration on a small number of sites in the first rows (Hindman, 2007) (Watanabe, 2013). In turn, as the majority of citizens using search engines limit their search to the first few entries on the list (Keane, et al., 2008); (Beiler, 2013); (Pan, et al., 2007); (Stark, et al., 2014), the democratization of news access provided by search engines is thus mostly limited to mainstream news sources.

At the same time, according to a study by Beiler (2013), the ranking of search results does not appear to be influenced by journalistic news values. In other words, if citizens construct their news diet mainly via search engines, this diet will differ dramatically from that presented by journalistic news organizations. 6 Most importantly, the news content accessed via search engines will be less diverse and foster the misperception of a consonant opinion climate based on the long lists of consonant duplicate entries in the search results.

In a similar manner, app stores can greatly facilitate access to a diverse range of news outlets which can all be accessed more easily compared to their offline counterparts, even encouraging previously disengaged citizens to consume news, for example during periods of boredom (Van Damme, et al., 2015). For regular news users, however, app stores do not lead to a more diverse news use: Most of them remain loyal to their established brands. In addition, apps stores require news suppliers to agree to the terms of services of the commercial app store providers which usually stipulate not only a high share of the revenue, but also access to customer data. As a result of this, some major news providers (e.g. the Financial Times) have created their own apps, while in particular smaller news outlets have chosen not to provide an app (Westlund, 2013).

\section{Filter-bubbles?}

Most of the new information intermediaries discussed here employ strategies of explicit and implicit personalization in order to increase user satisfaction and loyalty. Explicit personalization encompasses all tools which allow users to create interest profiles, subscribe to news feeds and mobile apps. In contrast implicit personalization is conducted without the active participation of the user through algorithms adapting the content to the individual user's interests based on his past click behaviour, his location and

\footnotetext{
${ }^{6}$ As Beiler (2013) points out, this may in the long run lead to a change in journalistic news values as online news sites attempt to optimize their findability via search engines.
} 
search behaviour (Thurman \& Schifferes, 2012). These personalization instruments, in particular the algorithms invisible to the common user, are feared to create for each user a "personal ecosystem of information" or a so-called "filter bubble" (Pariser, 2011), in which they are no longer confronted with attitude-discrepant information.

However, a number of studies have shown the reluctance of users to put any form of effort into a personalization of their news supply (Gauch, et al., 2007); (Thurman \& Schifferes, 2012), despite the fact that personalization has been shown to improve users' attitude and loyalty to websites (Kalyanaraman \& Sundar, 2006). This may in part be due the discrepancies between users' declared interests and actual news interests (Lavie, et al., 2010). In other words, the feared reduction in the diversity of supply through explicit personalization only applies to a small number of users.

In order to assess whether the feared filter bubble actually exists, researchers would have to analyze on the one hand the personalized news experiences provided by implicit personalization features of news sites and apps, and on the other the personalized outputs of the collaborative filtering mechanisms (such as "recommendations by other users") used by all new intermediaries. The social network Facebook has recently provided a first empirical study of the polarization of news via its platform (Bakshy, et al., 2015): Based on an automated content-analysis of the news encountered by all US users who identified as either Conservative or Liberal on the network they can show that even though in Facebook as a whole there is a lot of cross-cutting news content available, the content shared within one's personal network is a lot less diverse, in particular for Liberals (only 24 percent compared to 35 percent for Conservatives), due to their politically homogeneous friendship networks. The Facebook newsfeed algorithm further reduces diversity. However, in the case of the Conservatives, the main reduction in exposure diversity then occurs through personal choice: they are less likely to click on a cross-cutting link. It Nevertheless, it should be considered problematic that users have no knowledge of the selection criteria on which the processes of implicit personalization are based and that they are not provided with any tools to change them or turn them "off". Thus they are unable to assess how limited their news selection is. As research on selective exposure has shown, individuals perceive a greater need for orientation in specific situations (for example during election campaigns) and are then more willing to engage with attitude-discrepant news (Garret, 2009). Without any specific knowledge and control of the implicit personalization processes, they would be unable to reverse it in case of need.

There is also no evidence that (personalized) search engines and news aggregators increase the passive selective exposure to attitude-consistent news among their users (Mutz \& Young, 2011). In fact, a main finding of the research on selective exposure remains that though users may prefer to consume attitudeconsistent content, they invest little effort in avoiding attitude-discrepant news. On the contrary, when confronted with attitude-discrepant news, they tend to invest more time reading and processing the information (Garret, et al., 2013).

Therefore even though traditional media outlets offer more opportunities for users to "accidentally" encounter opinion challenging information (which they could choose not to read/watch, but they would still notice its existence), there is no evidence that the new information intermediaries strongly inhibit contact to attitude-discrepant news. They may curtail these opportunities somewhat and increase the 
effort required to access this content (another link to click), which in turn could facilitate the avoidance of attitude-discrepant news. However, despite the existence and substantial use of search engines and news aggregators, most empirical studies report continuing significant audience overlaps in particular for moderate news outlets (Garret, et al., 2013)).

In social networks, users have been shown to follow, mention and reply in particular to other users with similar views (Himelboim, et al., 2013). Commentators on partisan Facebook pages also mostly provide ideology-consistent links (Robertson, et al., 2009). Though this does imply limitations of exposure diversity in these networks, there is also empirical evidence of cross-cutting exposure and conversation: Though partisan users disproportionally talk with likeminded others on Twitter, they do not ignore those with differing opinions (Borah, et al., 2013); (Himelboim, et al., 2013).

\subsection{Gatekeeper as controller of critical intermediary resources}

In contrast to the gatekeeper as a controller of access to and supply of information, , the influence of the gatekeeper as controller of critical resources is more of a structural nature. Through the control of certain critical technical, legal or logistical resources that are needed for information to travel between sender and receiver, these gatekeepers are able to influence the structure of information markets and competition, either directly, or indirectly.

\section{Monopolisation of information access?}

Survey results in several countries indicate that consumers' use of news outlets is varied, choosing from many outlets. Trilling (2013) gathered survey data in the Netherlands that shows that Google News is used by $14 \%$ of the population for the consumption of news. Considering all possible news outlets, there are 23 outlets that are used more often than Google News. If we consider only websites, Google News ranks fifth. In Germany, a fifth of the population turns to search engines for opinion forming on political topics, while a quarter relies on access portals of mail providers (news aggregators), (Hasebrink \& Schmidt, 2013). A comparative study in eight Western countries reports comparable figures for social media which are considered to be an important news source for about a fifth (Japan, France, Germany, UK) to a quarter(Italy, Spain, US, Denmark) of the population (Nielsen \& Schrøder, 2014). Still, traditional news outlets such as television, online news sites of traditional outlets and print newspaper remain by far the dominant sources of information. The picture that emerges is therefore that the informational intermediaries are not essential gatekeepers in the traditional sense of controlling a resource access to which is necessary to reach the audience: consumers can do without them to obtain news and information.

\section{Generating network effects}

Another, more structural consideration is that of market/opinion power. Network effects play a role in the platform types: a consumer prefers to use the social network where many other consumers are. An app user wants to use the platform that features many app sellers, and vice versa: the app seller prefers the platform used by as many users a possible. Hence, the social network and the appstore are so-called 
two-sided markets. It is well-known in the literature that an equilibrium can sustain only a small number of such intermediaries and a concentrated market structure is thus expected (Belleflamme \& Peitz, 2010). The analysis is different for the search engine. Consumers care about the results they get, but arguably not about the types and number of other users using the search engine. Website owners care about being included in search results but typically all websites are included in the algorithms of all search engines in the market (put differently, website owners multi-home).

\section{But also: encouraging and facilitating production of news content?}

But there are also potentially positive structural factors. For example, even though the new information intermediaries rarely produce news content themselves, their existence, i.e. the infrastructure they provide, undoubtedly encourages the production of news content by others: Search engines can increase the findability of independent news sites or blogs that lack the funds and reputation to generate enough traffic on their own. Through this, formerly passive news users are encouraged to create their own commentary and content (Singer, et al., 2011); (Himelboim \& McCreery, 2012), and to thus become "produsers" (Bruns, 2008)) or "citizen journalists" (Gillmor, 2004). Content platforms such as Youtube may also stimulate the production of news content by non-journalists. And social networks provide a framework in which people outside of traditional news organizations can create and distribute their own news content. In addition, the collaborative filtering on social media platforms can assist new voices without the support of large news or political organizations to gain in popularity and visibility. For this reason, social networks are sometimes credited with being able to create an alternative news agenda, for example during the Arab spring (Newman, 2011) (Papacharissi \& de Fatima Oliveira, 2012).

The question remains, however, in how far these opportunities actually contribute to an increased diversity of supply and exposure compared to the offer of traditional media outlets. Even though the new information intermediaries may have made it easier for a broader range of people to produce news and editorial content, there still exist significant barriers, ranging from internet access and the necessary technical equipment to the required computer skills (Larsson, 2012). In addition, the confusing intellectual property rights may hamper citizens' initiative to contribute (Lessig, 2008). Here the new information intermediaries on the whole provide no assistance to lay users, neither through publishing guidelines nor by protecting them from prosecution by copyright lawyers.

A number of empirical studies on the "new" content producers point to a persistent digital divide related to the production of online editorial content with significant variations between different platforms and formats (as well as for different countries): In particular the blogosphere appears to be dominated by wealthy and well-educated men (Dutton, et al., 2009); (Lenhart \& Fox, 2006); (Tremayne, et al., 2006). And in most countries only a small minority of the population contributes political content via social networks, discussion fora or weblogs (Austria: (Vonbun \& Schönbach, 2014); NL: (Bakker, 2013); Germany: (Emmer, et al., 2012); US: (Baek, et al., 2012); Sweden: (Östman, 2012); France: (Jouët, et al., 2011).

Analyses of citizen journalists' contributions have criticized their focus on soft news (Örnebring, 2008), (Pantti \& Bakker, 2009) or on personal, non-political issues (Lenhart \& Fox, 2006); (Papacharissi, 2009); (Trammell, et al., 2006), but also pointed out an overall greater diversity of topics and outside sources 
(Carpenter, 2010). On social networks, the share of original news content is rather limited, the majority of political "news" in fact links to the content of major news outlets, with Facebook emerging as the second to third important driver of traffic to US news sites (Olmstead, et al., 2011). Similarly, journalists successfully promote their work on Twitter and generate traffic to their news website (Ju, et al., 2013), with 75 percent of shared news on Twitter in the UK linking to traditional news outlets (Newman, 2009).

\section{Wider influences on structure and practice of media markets}

Information intermediaries can affect also the future economic models for the media, by impacting business models or entering into direct economic competition (Foster, 2012; Hoppner, 2013). On the other hand, they directly support and also affect the practice for the media through their use by journalists. Studies of journalists' work habits in Germany have shown that they heavily rely on search engines for a number of purposes, including the search for counter-arguments. In the perception of the journalists, search engines greatly facilitate their work (Neuberger, et al., 2009); (Machill \& Beiler, 2009). However, most of them use one search engine exclusively (Google) and also do not display a more sophisticated use of search engines than the average user, rarely going beyond the first entries on the search list. They therefore do not take full advantage of the diversity of supply offered by these intermediaries. In a similar manner, journalists only employ a very small range of news aggregators (mainly Google News) (Springer \& Wolling, 2008).

Social networks, in particular Twitter, are also increasingly employed by journalists as news sources themselves or gateways to news sources. A comparative analysis of the use of Twitter in the coverage of British and Dutch elections indicates that the impact on diversity of supply strongly dependent on the national twitter sphere and its political discourse culture: While in the Netherlands politicians could increase their chances of being quoted in the media, British media used Twitter more strongly to give voice to ordinary voters (Broersma \& Graham, 2013)).

Finally there are also wider concerns that are not directly related to the generation, accessibility, findability etc. of diverse and plural content, but about the conditions and how this affects fundamental rights and freedoms. For example, this can refer to the impact of personalization and targeting strategies on user freedom and autonomy (Zarsky, 2003), shared cultures and values (Schoenbach, 2007), democratic participation (Sunstein, 2007) and diversity of media consumption (the filter bubble argument) (Pariser, 2011), but also social sorting and discrimination (Zarsky, 2003). Concerns have also been raised with regard to social networks that these are the property of companies which may act as "quasi-governmental regulators" who "govern citizenship rights in their respective online territories" and can exclude specific users or user groups (Busch \& Sheperd, 2014).

Concluding, a look into the existing empirical research on the impact of the new information intermediaries on media diversity thus reveals some important points: First, the new information intermediaries exercise editorial control to comply with local legislation or sensibilities. Though their interventions are not likely to be politically motivated, their staff lack the journalistic training, professional norms and control structures to reflect on the impact of these editorial decisions, making them susceptible to outside influences aiming to reduce diversity. In their aim to avoid conflict with political 
authority they seem unlikely to fulfil the role of professional journalists by stimulating public debate. This seems particularly problematic as Facebook is now making deals with news agencies and news publishers in order to provide its own news content.

Second, though we still lack the necessary systematic (independent!) research to determine the impact of indirect editorial control exercised through ranking and personalization features, the existing preliminary research seems to indicate that the filterbubble concern, as one of the most prominent advanced in public policy discourse, is a lesser threat/problem for media diversity. Nevertheless, it seems problematic that the new information intermediaries lack the incentives and will to provide diverse content while functioning as main portal for media access and defining parameters of choices for users.

Third, though search engines, social networks and app platforms can play an important role in access to and choice of media content, users do not per se need to use them to access media content - the content is available in any event. Therefore, neither search engines, social networks nor app platforms are likely to be structural gateways or bottlenecks in the traditional economic sense.

Based on the research discussed above it emerges that the main obstruction for greater exposure diversity through the new information intermediaries is the user herself who does not seem to place much importance on diversity of information. This is not a new phenomenon, however, both the indirect editorial and structural control of the new information intermediaries may compound this tendency and through this turn it into a significant problem: Through their past usage, media users will continuously narrow down the information choices available to them - and most of them will not even notice this. They will also lack the knowledge, skills and possibilities to "turn it off" should the need for more diverse information arise.

\section{Discussion}

\subsection{A critical view on a critical discourse}

After having provided an overview of the different concerns with respect to new information intermediaries, such as search engines, social networks and app platforms, and the empirical evidence so far, this section will consider the wisdom of applying traditional gatekeeper concepts and remedies to the new information intermediaries. It will also develop first contours of an alternative or complementary approach.

\section{What exactly is the problem?}

Maybe the most striking conclusion from the ongoing discussion, but also from the empirical research surveyed in section 2 , is that for the time being there is still considerable ambiguity and uncertainty if and maybe even more importantly: under which conditions search engines, social networks and app platform are indeed gatekeepers to diverse information access. As section 23.2 shows for example, the much cited filter-bubble problem is far from being proven, and diverts attention from the fact that e.g. search engines 
can also have a positive effect through increasing choices and findability, as well as offering new opportunities for bottom-up editors and news production. The new information intermediaries do not have the incentives to show diverse content (in a normative sense) but then this is not what their services are about and for which users use and value them. All three are popular means for users to access news content, and yet, for media content on social networks and search engines at least, users commonly have alternatives to that particular intermediary for accessing the content it provides. That is, the informational intermediary does not limit access for users that know what they want, where to find it, and are willing to invest the necessary energy.

The potential for gatekeeping lies in such cases at least much more in affecting the choices made by users that do not know yet what content to consume or where to find it. Having said that, whether this amounts to a problem for media diversity depends ultimately on whether the choices users make are 'sufficiently diverse'. ${ }^{7}$ This is a question, however, that cannot be decided with the traditional measurements of media diversity as it affects not the supply side but the demand side of information markets, i.e. the aspect of exposure diversity. For the time being, and as explained earlier, however, we lack normative conceptualizations of exposure diversity that would allow us to identify a critical threat to media diversity, even if there is one. Ofcom was, to the knowledge of this author, also one of the first regulatory authorities that at least considered some more detailed suggestions for more comprehensive benchmarks to measure not only the state of media diversity, but also whether overall output AND consumption is sufficiently plural, to address the question of both content and exposure diversity (Ofcom, 2012).

The lack of a conceptualization of exposure diversity touches upon another, related problem, namely the limited role that user preferences have played in the discussion so far. For example more diverse search results could conflict with their quality (Van Hoboken, 2012): instead of receiving the most relevant search result in relation to a query a user would be presented with possibly less relevant but diverse suggestions. In other words, media diversity are not the only, and also not automatically the dominant values to consider. Insofar it would also be important to look into the preferences of the users, and the reasons for which they use a search engine or social network. ${ }^{8}$

\footnotetext{
${ }^{7}$ A discussion that has received some attention, for example, in the UK. In response to the House of Lords Select Committee on Communications Report into Media Plurality, the Department for Culture, Media and Sport stated explicitely that it considered a decision whetehr or not to develop statutory or non-statutory guidance defining the meanfin of sufficiency of plurality premature, and instead stressed the importance of waiting until Ofcom had completed teh development of the measurement framework, (Department for Culture, 2014, p. 24)

${ }^{8} \mathrm{~A}$ claim that has been advanced by economics already for a long time. For example, Michele Polo observed in the context of broadcasting: "If we think that the general public is in the position to make informed and independent choices on the media or programme/article to patronise, availability of different views should be all that matters; if we presume that the public always chooses its preferred political contents, the ex post observation of actual choices should simply reflect the distribution of preferences, over which we should be neutral." (Polo, 2007, p. 153). If, on the other hand, consumers' choices are distorted by lock-in or other frictions such as bundling of content, their choices may not reflect their preferences and regulatory action may be warranted even when the available supply is considered to be sufficiently diverse.
} 


\section{Falling outside existing legal gatekeeper concepts}

Apart from the need for evidence that there is an actual problem for (exposure) diversity, the previous analysis has also made clear that the new information intermediaries do not fit easily into the existing gatekeeper categories, at least not the legal ones. From the legal perspective, search engines, social networks and app platforms were so far considered as a so-called information society service. ${ }^{9}$ As such they benefitted from relative immunity as regards more content-related obligations (such as to ensure a diverse representation of offers), as a result of the E-Commerce safe harbour provisions for hosts. ${ }^{10}$ More lately, however, there have been calls for more "algorithmic governance in the public interest" (Napoli, 2014) (see also (Laidlaw, 2010) and imposing editor-like obligations for the societal quality of their output. In the recent scholarly and policy debate various suggestions have been made to impose some form of diversity safeguards on (selected) information intermediaries (including suggestions for objective point systems, prominent display of public interest or diverse news sources, internal diversity safeguards or a diversification of search queries ( (Danckert \& Mayer, 2010; Foster, 2012). Probably the most extreme standpoint so far has been advanced by Kreile and Thalfhofer, who essentially suggest to apply media law and its diversity safeguards to search engines (Kreile \& Thalhofer, 2014, pp. 635-637).

The problem with these suggestions is obvious. The applicability of the previously described safeguards is commonly triggered by the qualification of a search engine or social network as 'editor' in the legal sense (which is not identical with the more flexible ways in which the notion is used e.g. in the communications sciences). Though no common legal definition of an "editor" exist, the Audiovisual Media Service Directive may give some indication of what editorial control means in the legal sense: "the exercise of effective control both over the selection of the programmes and over their organisation either in a chronological schedule, in the case of television broadcasts, or in a catalogue, in the case of on-demand audio-visual media services." ${ }^{\prime 11}$ It is already questionable to what extent such an activity is at all compatible with the business model of a general purpose search engine ${ }^{12}$ what impact this would have on the overall structure of, and competition within media markets, but also what the other legal implications would be.

Another important and not yet decided question in this context is to what extent algorithmic, technological-mediated control can be classified as editorial or editor-like control at all, as they are for large part subject to automated process. From all this it already becomes clear that the emergence of new information intermediaries' questions established concepts of editorial control as a central criterion for the application of traditional rules on media regulation and information diversity. ${ }^{13}$

\footnotetext{
${ }^{9}$ Defined as „any service normally provided for remuneration, at a distance, by electronic means and at the individual request of a recipient of services", Art. 2 (a) of Directive 98/48/EC of the European Parliament and of the Council of 20 July 1998

amending Directive 98/34/EC laying down a procedure for the provision of information in the field of technical standards and regulations.

${ }^{10}$ Art. 14 of Directive 2000/31/EC of the European Parliament and of the Council of 8 June 2000 on certain legal aspects of information society services, in particular electronic commerce, in the Internal Market ('Directive on electronic commerce').

${ }^{11}$ Art. 1 (c) of the Audiovisual Media Service Directive.

${ }^{12}$ Critical e.g. Paal, p. 55, pointing to the technical impossibility of such a "Algorithmus der Meinungsvielfalt”, also in the light of the sheer number of daily search requests (Paal, 2012).

${ }^{13}$ But see also Neuberger \& Lobgis, arguing that navigation and moderation are editorial activities, though with a lesser influence on public opinion forming (Neuberger \& Lobgis, 2010), p. 155.
} 
At the other end of possible regulatory measures discussed are structural remedies with the goal to discipline gatekeepers as controllers over critical resources, respectively control the amount of power they are able to exercise over information markets. One possible avenue discussed are access and due prominence obligations, similarly to those that apply to cable networks, pay-TV platforms and EPGs ( (Foster, 2012), (Danckert \& Mayer, 2010; Schulz, et al., 2011; Paal, 2012). But again, neither search engines, social networks nor app platforms fit easily into the definition of a controller of an electronic communications service, respectively an associated facility, which, however, would be necessary to qualify for the application of the Access Directive's access obligations (Helberger, 2005). The question is then to what extent the existing definitions could and should be extended to also cover the new information intermediaries (see e.g. the suggestion by Kreile and Thalhofer (Kreile \& Thalhofer, 2014, p. 636)- a question of great relevancy e.g. in the upcoming revision of the Audiovisual Media Service Directive. Much will depend on whether there is sufficient empirical evidence to support the need for an inclusion (critical section 2.3 and 2.4), e.g. because there actually is a challenge to media diversity.

And even if there is such a challenge, it is important to realize that, though search engines, social networks and app platforms may share certain characteristics of the more traditional gatekeepers, such as editors and controllers of pay-TV platforms, they also differ from the traditional gatekeepers in various ways. The differences are best explained with the help of a theoretical conceptualization of gatekeeper. Many of the existing conceptualization vary according to the discipline in question, and most have not been devised with the digital networked environment in mind. One exemption is Barzilai's Theory of Network Gatekeeping, which has been inspired exactly through the lack of a comprehensive theory of network gatekeepers (Barzilai-Nahon, 2008).

\section{Static concepts where the digital networked environment calls for more dynamic ones}

Barzilai analyzed various conceptualizations of gatekeepers, as developed in communication science, information science and management literature. Most conceptualisations still focus primarily on the role of the gatekeeper, rather than the question of how networks, such as the internet or a social network, affect relations between gatekeepers and those who are subject to gatekeeping: the 'gated?. (BarzilaiNahon, 2008, pp. 1494-1495). As demonstrated earlier, however, in a networked environment it is exactly this relationship between gatekeeper and gated (e.g. users) that accounts much for the dynamics, influence and salience of an online gatekeeper. Consequently, existing conceptualizations are little useful in identifying gatekeeper situations online. At a similar conclusion arrived Laidlaw who criticized the "one way approach of traditional gatekeeping theory" and observed in addition that in "a Web 2.0 world the gated are not static, but rather dynamic players in creating and managing the Internet environment." (Laidlaw, 2010, p. 266). These observations are certainly also relevant for the traditional legal conceptualization of gatekeeper which also do not hold any account to the role of users, nor do users and the gatekeepers' relationship to the user play any significant role in imposing legal obligations or diversity requirements. 
Barzilai then moves forward to develop a more differentiated conceptualization of gatekeepers, where she differentiates between gate, ${ }^{14}$ gate keeping, ${ }^{15}$ gated, ${ }^{16}$ gatekeeping mechanism, ${ }^{17}$ and network gatekeeper. ${ }^{18}$ One important observation of hers is that not only the gates can differ, but also e.g. the different mechanisms of gatekeeping - another observation that is not yet reflected in either law nor the public policy discourse surrounding information intermediaries and their potential role as gatekeepers or bottlenecks for access to a diverse media offer.

An operator of a pay-TV platform, for example, exercises gatekeeping power via what Barzilai coined the infrastructure mechanism: through the utilization of infrastructure components a pay-TV provider controls information and the behaviour of the gated (which could be both, providers of content as well as users) as well as cost-effect mechanisms, e.g. controlling the costs of joining, using and exiting the platform. Arguably, something similar could be said from an app platform, which through its control of the platform and its technical infrastructure is able to decide who has access and at which costs. This creates monopoly power (Belleflamme \& Peitz, 2010). Insofar, an argument could be and has been made (see above) in favour of applying similar rules of access to app platforms. However, as explained in section 2.3 and 2.4, the particular gatekeeping mechanism that marks the activities of e.g. a social network or a search engine is the high level of interaction between the platform and users, respectively the provision of value added services, such as personalization features, enhanced possibilities of interacting with other users of the network (through e.g. like buttons, tagging, commenting on each other's' time line, ...) and defining different levels of connectedness for different sorts of 'friends'. Here, in terms of gateway control and potential influences for media diversity, access to the platform is probably far less an issue. Rather it is the possibility to influence and manipulate individual choices.

Similarly, in the case of search engines, it is probably less access to the search engine that is characteristic for the search engines influence on (exposure) diversity, but rather the ability to determine the criteria for selection and diverse exposure (see section 2.3.2), channel attention and increase the loyalty of the user by offering ever-more personalized and fine-tuned search results. These examples also demonstrate that one of the challenges (or opportunity for) the realization of media diversity in both cases is the organization of, and control over the gated. Access obligations will do little to mitigate this problem.

The dynamics between gatekeepers and gated is also a factor that distinguishes traditional editors from e.g. search engines or social networks. Whereas in the traditional media it is primarily the editor who determines the agenda and thereby, at least indirectly, also information consumption, this is very different for e.g. search engines and social networks. Here, users or "the gated" have a far more active role, build into the system, in determining the actual information they get to see, respectively the diversity

\footnotetext{
${ }^{14}$ Which Barzilai defines in her paper as "entrance to or exit from a network or its sections".

${ }^{15}$ Defined as "the process of controlling information as it moves through a gate".

${ }^{16}$ Defined as "the entity subjected to gatekeeping".

${ }^{17}$ Defined as "as a tool, technology, or methodology used to carry out the process of Gatekeeping".

${ }^{18}$ Defined as "an entity (people, organizations, or governments) that has the discretion to exercise gatekeeping through a gatekeeping mechanism in networks and can choose the extent to which to exercise it contingent upon the gated standing".
} 
of choices, for example by means of the search terms that they feed into the system, or their selection of friends (see section 2.3.2). Because of the intensified interactivity with, and active involvement of users, maintaining one-directional conceptualizations of editorial control is actually very difficult.

This also questions the wisdom of applying editor-like obligations to e.g. search engines and social networks. One may question already to what extent such interferences would be actually need and justified as long as no demonstrable negative effect on media diversity (and exposure diversity in particular has been proven. The current lack of any concrete benchmarks to identify potential threats to exposure diversity does not make this assessment easier. But even if there was such a need: unlike for traditional editorial offers, the actual output (e.g. the search results) are very much depending on the interaction with, and input from the users. What is more: one salient feature about social networks is that they 'empower' users to discover and recommend others contents, thereby contributing to new forms of (exposure) diversity. A more pro-active, editorial involvement of social networks could have an inhibiting effect on such forms of 'bottom-up diversity'. Finally, imposing editorial responsibility on intermediaries may even increase, rather than decrease impact and opinion power of such intermediaries. Seeing the enormous reach that leading social networks and search engines have it could be even rather disconcerting to know that they are legally mandated to actively influence user choices, diverse or not.

To conclude, in the light of the insights about the importance of also taking the dynamics between gatekeeper and gated into account, arguing in favour of editor-like or access obligations shifts attention away from the real challenge to the realization of diverse offer and consumption. Arguably, this is not so much the ability or inability of the search engine to make sure the search results reflect a certain diversity of information, but rather the ability to influence, on the basis of the accumulated knowledge about, and the interaction with the user, her informational choices. Insofar, and as Laidlaw argues (Laidlaw, 2010), there is also a need for a more human-rights driven conceptualization of gatekeepers and the need to pay more attention, as Helberger demonstrated, to the relationship between gatekeepers and gated, and legal safeguards in the form of user rights as a way of dealing with gatekeeper control (Helberger, 2005). Or as Tambini so aptly observed: "Whilst regulators focus on the structural, legal and economic reasons why markets may not function effectively, they sometimes neglect the human perspective, and fail to examine the reasons why consumers may be unwilling or unable to play their part" (Tambini, 2011).

\subsection{Contours of a more user-centred approach}

Barzilai's more dynamic conceptualization of gatekeepers and gatekeeping mechanisms is also useful for another reason. Part of her theory is also the identification of attributes that determine the ability of the gated to exercise influence on the gatekeeper. ${ }^{19}$ Those attributes are

- Gated's power in relation to the gatekeeper,

- their information production ability,

- their relationship with the gatekeeper and

\footnotetext{
${ }^{19}$ Barzilai herself defines salience as „the degree to which gatekeepers give priority to competing gated claims (Barzilai-Nahon, 2008, p. 1498).
} 
their alternatives in the context of gatekeeping.

These attributes can also provide a first starting point to reflect on the contours of a possible alternative, more user-centred approaches, one that is directed towards mitigating the degree of influence and power of gatekeepers on the gated, for example to influence diversity of consumption.

We concluded earlier that one of the most critical issue when discussing gatekeepers and media diversity is their ability to affect user choices and diversity of exposure, much more than the ability to restrict access. The more gatekeepers are able to influence individual exposure to information, and ultimately consumption choices, the larger is their potential influence on media diversity (bearing in mind that this influence could be neutral, positive or negative). ${ }^{20}$

We already expressed doubts as to what extent e.g. the obligation to grant (diverse) content providers access to their platform at fair, reasonable and non-discriminatory terms is an effective means to discipline gateway power of e.g. search engines and social networks. This is because even if access was the problem, obligating the openness of the platform will only go half the way to pave the way for diverse exposure - too much depends on the way media content is presented, in which order, context, etc. (see section 2.4). Moreover, presenting a diverse information offer is discriminatory in itself as it involves the making of diverse selections.

At first sight, the application of due prominence rules seems to be a step closer to acknowledging the importance of taking into account the relationship between gatekeeper and gated, following the example of Art. 6(4) of the Access Directive, which allows member states to impose additional presentational requirements on operators of EPGs (for example due prominence of local programming or the programs of the public interest content) (in this sense for example (Foster, 2012), (Danckert \& Mayer, 2010; Schulz, Dreyer, \& Hagemeier, 2011; Paal, 2012). The European Commission in its Green Paper on convergence also seems to be pointing towards a concept of positive discriminatory access. After having addressed the potentially problematic effects of information intermediaries for the realization of media freedom and diversity, the European Commission explicitly refers "must carry" rules and Art. 6 (4) of the Access Directive (European Commission, 2013).

And indeed, if research demonstrates that framing or positioning of particular information can have an effect on exposure diversity (see section 2.3.2), this could be an argument in favour of imposing some sort of editorial or due prominence requirements. The arguments against, however, become more evident when the solution is seen from the perspective of users, and their relationship to the information intermediary. There are, of course, operational challenges (what types or contents should be presented more prominently, who determines the types of content, how to deal with the issue of national media policies vs. international operation and reach, how to prevent capture and abuse, etc. But more importantly, imposing such due prominence requirements can actually result in a situation of reduced exposure diversity. Due prominence obligations also entail pre-defining partly what the audience gets to see. Arguably, this is a route towards creating alternative, but then publicly mandated 'filter bubbles'. At the same time, due prominence rules would increase the influence of a search engine or social network over individual information exposure, by reducing the ability of individual 'gated' users to interact and

\footnotetext{
${ }^{20}$ Another question, which falls outside the scope of this paper is to what extent this influence could be used to nudge users towards more diverse choices.
} 
influence the choices that are ultimately presented to her. This is Barzilai's point that one of the attributes that determines the salience of the gated in relationship to the gatekeeper is the ability to produce information herself, respectively take an active part in the production or presentation of information. In other words, instead of presenting each user with a selection of content, depending on the individual search term or choice of friends (and thereby already granting an inherent diversity of results due to the heterogeneity of the audience), there will be certain contents with a disproportionate share of public attention/opinion power, because they are presented to all users (by turning the search engine or social network in some kind of mega, transnational 'broadcaster' of messages in the public interest). Or put, again, differently, due prominence rules do little to alleviate the influence of the gatekeeper over the gated users, instead they further increase and re-emphasis such influence.

This is why here we would like to suggest a more user-centred approach to dealing with gatekeeper control, namely in mitigating the influence and improper bias (financial bias, advertiser bias, partisan bias, user-history-based bias) that search engines, social networks and app platforms have on users, and the diversity of their choices. We will do so alongside the four attributes that characterize, according to Barzilia, the relationship between gated and gatekeeper.

\section{Power in relation to the gatekeeper}

The first factor is political power, i.e. the ability to influence and get the other party to do what the first party wants. Barzilai helpfully further differentiates between the ability to decide between different alternative models of action, controlling the agenda and not presenting certain choices as well as using the bias of the system to influence choices, e.g. the choice to choose more diverse or to switch to another service/speaker.

One such inherent bias in the system is the creation of individual lock-ins or path dependencies through particularly the implicit personalization of choices (as shown in section 2.3.2 explicit personalisation will affect, if at all, only the small number of users who actively engage in personalising their news offer). Insofar, the suggestions made to enable users to switch off personalization or reduce the amount of personalization applied could be one building block in increasing the power of the gated in relation to the gatekeeper. This is because, as section 2.3.2 explained, without such a possibility to exercise power on the personalization process, users are not able to reverse it if they are interesting in getting a more diversified, not personalized view on certain topics.

Beyond having (diverse) choices and being aware of them, search engines, social networks and app platforms, because of the level of interactivity and their very detailed knowledge of the user have furtherreaching possibilities to influence individual choices. This is what Calo has referred to digital market manipulation (Calo, 2014). Essentially, digital market manipulation describes the possibilities that algorithmic profiling give internet players to identify and use personal preferences and biases for advancing their own motives and, often commercial agenda. Insofar, users experience in their relationship to e.g. an app platform or social network a new form of power asymmetry that they do not experience with traditional media: while they companies know a lot about the user, the user knows little about the company, how much and kind of information it collects about the user, with whom this information is shared, how this influences the selection of contents and information the user is exposed to, etc. What is more, due to the 'black box' nature of the informational intermediary, bias is a significant concern. This is 
why aspects such as protecting users privacy, right to fair data processing and protection from 'unfair commercial media practices' will gain more relevance also for the realization of public policy objectives, such as media diversity - aspects that so far have played only a very marginal role in the media diversity discourse.

\section{Information production}

The aspect of information production is of course most evidently relevant in challenging gatekeepers with editor-like ambitions. But also in the case of indirect editorial or structural influences, alternative means of information production as an element of controlling the influence and power of gatekeepers is an aspect that is worth considering. This is obvious for the position of news producers vis-à-vis search engines, social networks and app platforms. But users, too, can generate information or meaning, if not in the form of User Generated Content, then in the form of collaborative filtering and alternative, social and potentially more diverse recommendations. This is why we have expressed concern about suggestions to impose editor-like requirements on e.g. search engines or social networks, exactly because they can have a detrimental effect on the freedom of users to produce information and construct meaning.

But the aspect of information production has another side to it. As we also showed, search engines, social networks or app platforms can be means for users (including professional journalists) to produce information. The quality or overall diversity of such information, however, does not only depend on the information intermediary. It also depends on the users, be they amateurs or professionals. Section 2.4 explained for example that both, users and journalists, when using e.g. search engines to produce information tend to focus only on a very small selection of search results (the first few entries) as well as only a limited choice of information intermediaries. In other words, the production and consumption of diverse information, with the help of despite new information intermediaries, is also the outcome of the way how users use them. This is another insight from a more dynamic understanding of gatekeepers, and one that merits the question whether part of the solution to any concerns about media diversity and new information intermediaries should (also) be searched for at the level of users, for example by promoting media literacy and increasing the usability of information intermediaries for the less experienced users

\section{Relationship}

Arguably, this is a particular important aspect when considering ways to alleviate possible concerns about the gatekeeper position of new information intermediaries. It also relates to the discussion of 'power' earlier in this section. As Barzilai explains, the "existence of a direct connection and its endurance plays a major role by creating a venue for negotiation of stances between the gated and the gatekeeper." (Barzilai-Nahon, 2008, p. 1500). Such connections can be of a legal nature (terms of use, privacy policies), social (the relationships between users, but also the degree to which intermediaries mediate and facilitate social exchange between users), or even personal nature, depending on the knowledge about the user. Often, these relationships are characterized by considerable asymmetries. We already mentioned the power that detailed knowledge about the user gives to model that relationship, and the aspect of 'digital market manipulation'. 
Terms of use or the knowledge about users can be not only ways to establish a direct relationship with individual users, but also to manage that relationship, for example by creating lock-in effects and increasing the obstacles to switching. The more users have invested effort and personal data (photos, friends, posts) into a social network, switching networks involves higher costs. This is, for example, one of the reasons why in the discussions around the draft data protection regulation data portability plays a central role. Aspects of data protection law, or control of contracts (in the form of terms of use), so far have played no or only a very limited role in assessing the potential of intermediaries for the realization of media diversity. A more dynamic understanding of gatekeepers helps to understand the importance of considering these aspects, also in the diversity dialogue.

\section{Alternatives}

Clearly, the salience of a gatekeeper relationship also depends on the availability of reasonable alternatives. This is an aspect that has already been considered in the context of the more traditional gatekeeper discussions, e.g. in the context of pay-TV. One reason to mandate access to the conditional access system was to safe users from the need to purchase several settop boxes if they wanted to switch between pay-TV services. And indeed, creating alternatives has also be suggested as an alternative approach towards mitigating the influence of the new information intermediaries on diverse choices. Collins and Cave, for example, suggested to rethink media concentration measures with a view on lowering entry obstacles and increase supply, rather than to restrict economic or opinion power (Collins \& Cave, 2013). In a similar direction go suggestions for creating incentives or funding competing search engines, so that users can get a 'second opinion' (Schulz, et al., 2005).

But again, argued from the perspective of the gated, and their relationship to the gatekeeper, one soon recognizes that having alternatives is one aspect, being aware of them is another, and maybe the more critical one under conditions of digital abundance. Another relevant aspect that should deserve more attention when discussing ways of mitigating gatekeeping control over diverse information exposure is therefore the aspect of making users more aware of the choices they have. Interestingly, a variety of tools have been developed to make users aware of the (narrowness) of her choices, including tools such as Bobble, Considerit or Scoopinion.

\section{Conclusions}

Information markets are changing, so are information intermediaries. One salient feature of the new information intermediaries, such as search engines, social networks and app platforms is a far more interactive, dynamic and complicated relationship with users. Accordingly, many of the potential influences of these new information intermediaries are related to exposure diversity and the ability of the new information intermediaries to influence information choices, or set the parameters for the way users make their choices. Accordingly, when examining to what extent the new information intermediaries are gatekeepers for diverse information markets and more diverse exposure, a more dynamic conceptualization of gatekeeping is needed, one that also takes into account the relationship between 
gatekeeper and gated. Barzilia's Theory of Network Gatekeeping provides a useful analytical framework in that context.

Applying her theory, it becomes quickly clear that, and why and on which points old and new gatekeepers differ. One important aspect are the mechanisms to exercise gatekeeping control, which in the case of search engines, social networks and application platforms are often related to the interactivity with users, and the amount of knowledge and control over the user base, and exposure to diverse information. This article has suggested that this is also one reason why it is questionable whether applying 'old' tools that focus primarily on imposing obligations for the gatekeeper of how to behave in relation to other content providers are sufficient in addressing gateway concerns with regards to new information intermediaries, such as search engines, social networks and app platforms. Instead, this paper has developed the contours of a more user-centred approach - an approach that takes more into account the dynamics between gatekeeper and gated, and seeks to re-establish the opportunity for users to exercise power through exit or making alternative choices.

Finally, all regulatory measures considered must keep in mind that information intermediaries have potentially both, negative as well as positive implications for media diversity, as they are also enablers of media diversity. The question for policy makers is therefore whether policy interventions can optimize media diversity while at the same time not deterring companies from offering their services.

\section{References}

Kommission zur Ermittlung des Konzentrationsbedarfs - KEK, 2010. 4. Medienkonzentrationsbericht, Auf dem Weg zu einer Medienuebergreifenden Vielfaltssicherung, sl: sn

Almiron-Roig, N., 2010. Regulation of pluralism in France. Context, analysis and interpretation. Revista Latina de Comunicacion Social;; pp. 472 - 487.

Baek, Y., Wojcieszak, M. \& Delli Carpini, M. X., 2012. Obnline versus face-to-face deliberation: Who? Why? What? With what effects?. New Media \& Society, pp. 363-383.

Bahr, M., sd Rechtsanspruch auf Aufnahme in den Suchmaschinen-Index (am Beispiel Google)?. [Online] Available at: http://www.suchmaschinen-und-recht.de/rechtsanspruch-auf-aufnahme-in-densuchmaschinen-index.html 
Bakker, T., 2013. Chapter 2: The people still kown as the audience: The limited political use of online participatory media. In: Citizens as political participants: The myth of the active online audience? . Amsterdam: Dissertation submitted to the Faculty of Social and Behavioural Sciences, pp. 21-46.

Bakshy, E., Messing, S. \& Adamic, L., 2015. Exposure to ideologically diverse news and opinion on Facebook. Science, 7 5, pp. 1-5.

Barzilai-Nahon, K., 2008. Toward a theory of Network Gatekeeping: A Framework for Exploring Information Control. Journal of American Society for Information Science and Technology, pp. 14931512.

Beiler, M., 2013. Nachrichtensuche im Internet. Inhaltsanalyse zur journalistischen Qualität von Nachrichtensuchmaschinen. Konstanz: UVK.

Beiler, M., 2013. Nachrichtensuche im Internet. Inhaltsanalyse zur journalistischen Qualität von Nachrichtensuchmaschinen. Konstanz: UVK.

Beisch, N. \& Engel, B., 2007. Wie viele Programme nutzen die Fernsehzuschauer? Analyse zum Relevant Set. Media Perspectiven, pp. 374-379.

Belleflamme, P. \& Peitz, M., 2010. Industrial Organization: Markets and Strategies. Cambridge: Cambridge University Press.

Berman, R. \& Katona, Z., 2013. The Role of Search Engine Optimization in Search Marketing. Marketing Science, 32(4), pp. 644-651.

Borah, P., Edgerly, S., Vraga, E. K. \& Shah, D. V., 2013. Hearing and talking to the Other Side:

Antecedents of Cross-cutting Exposure in Adolescents. MAss Communication and Society, pp. 391-416.

Breemen, V. \& Breemen, K., 2013. YouTube onder de loep. Is er plaats voor UGC platforms in de veilige havens van de E-Commerce Richtlijn?. Amsterdam: DeLex.

Broersma, M. \& Graham, T., 2013. Twitter as a news source. How Dutch and British newspapers used tweets in theirr news coverage, 2007-2011. Journalism Practice, pp. 446-464.

Bruns, A., 2008. Blogs, wikipedia, second life, and beyond: From production to produsage. New York: Peter Lang.

Busch, T. \& Sheperd, T., 2014. Doing well by doing good? Normative tensions underlying Twitter's corporate and social responsibility ethos. Convergence: The international Journal of Research into New Media Technology.

Calo, R., 2014. Digital Market Manipulation. George Washington Law Review, pp. 995-1051.

Carpenter, S., 2010. A study of content diversity in online citizen journalism and online newspaper articles. New Media \& Society, pp. 1064-1084. 
Collins, D. A. \& Cave, M., 2013. Media pluralism and the overlapping instruments needed to achieve it. Telecommunications Policy, pp. 311-320.

Cooper, R. \& Tang, T., 2009. Predicting Audience Exposure to Television in Today's Media Environment: An Empirical Integration of Active-Audience and Structural Theories. Journal of Broadcasting \& Electronic Media, pp. 400-418.

Corniere, A. d. \& Taylor, G., 2014. Integration and search engine bias. The RAND Journal of Economics, pp. 576-597.

Council of Europe, 1999. Recommendation No. R(99)1 of the Committee of Ministers to Member States on Measures to Promote Media Pluralism, Strasbourg: Council of Europe.

Council of Europe, 2007. Recommendation No. R(2007)2 on media pluralism and diversity of media content, Strasbourg: Council of Europe.

Council of Europe, 2008. Recommendation CM/Rec(2008)6 of the Committee of Ministers to member states on measures to promote the respect for freedom of expression and information with regard to Internet filters, Strasbourg: Council of Europe.

Council of Europe, 2012. CM/Rec(2012)3 of the Committee of Ministers to member states on the protection of human rights with regards to search engines, Strasbourg: Council of Europe.

Craufurd Smith, R. \& Tambini, D., 2012. Measuring Media Plurality in the United Kingdom: Policy Choices and Regulatory Challenges. Journal of Media Law, pp. 53-63.

Craufurd Smith, R., Tambini, D. \& Morisi, D., 2012. Regulating Media Plurality and Media Power in the 21st Century, London: LSE Media Policy Project: Media policy brief 7.

Danckert, B. \& Mayer, F. J., 2010. Die vorherrschende Meinungsmacht von Google. MMR, p. 219 subsq.. de Corniere, A. \& Taylor, G., 2014. Integration and Search Engine Bias. The RAND Journal of Economics, 45(3), pp. 576-597.

Department for Culture, M. \&. S., 2014. Media Ownership \& Plurality Report. Government response to the House of Lods Select Committee on Communications Report into Media Plurality, London: sn

Donahue, G., Tichenor, P. \& Olien, C., 1972. Gatekeeping: Mass Media Systems and INformation Control. In: Current Perspectives in Mass Communication Research. Beverly Hills: Sage, pp. 41-70.

Donsbach, W. \& Patterson, T. E., 2004. Political News Journalists: Partisanship, Professionalism, and Political Roles in Five Countries. In: Comparing Political Communication - Theories, Cases, and Challenges. Cambridge: Cambridge University, pp. 251-271.

Duff, A. S., 2012. A Normative Theory of the Information Society. Oxford: Taylor and Francis: Routledge Research in Information Technology and Society. 
Dutton, W., Gerber, W. \& Helsper, E., 2009. The Internet in Britain 2009. Oxford: Oxford Internet Institute.

Emmer, M., Wolling, J. \& Vowe, G., 2012. Changing political communication in Germany: Findings from a longitudinal study on teh infleunce of teh Internet on political communication, discussion and the participation of citizens. Communications. The European Journal of Communication Research, pp. 233252.

Esser, F. et al., 2012. Political Information Opportunities in Europe. The International Journal of Press/Politics , 3 17, pp. 247-274.

European Commission, 2007. media pluralism in the member states of the European Union, Brussels: European Commission.

European Commission, 2010. Communication from the Commission to the European Parliament, the Council, the European Economic and Social Committee and the Committee of the Regions. A digital agenda for Europe, Brussels: sn

European Commission, 2013. Green Paper. Preparing for a fully converged world: Growth, Creation and Values, Brussels: European Commission.

Ferguson, D. \& Perse, E., 1993. Media and Audience Influences on Channel Repertoire. Journal of Broadcasting \& Electronic Media, pp. 31-47.

Foster, R., 2012. News Plurality in a Digital World, London: Reuters Institute for Journalism.

Frijters, P. \& Velamuri, M., 2010. Is the Internet Bad News? The Online News Era and the Market for High-Quality News. Review of Network Economics, 9(2).

Gandal, N., 2001. The dynamics of competition in the internet search engine market. Evolution of Markets, 19(7), pp. 1103-1117.

Garret, R. K., 2009. Echo chambers online? Politically motivated selective exposure among internet news users. Journal of Computer-Mediated Communication, pp. 265-285.

Garret, R. K., Carnahan, D. \& Lynch, E., 2013. A Turn Towards Avoidance? Selective Exposure to Online Political Information, 2004-2008. Political Behaviour, pp. 113-134.

Gauch, S., Speretta, M., Chandramouli, A. \& Micarelli, A., 2007. User profiles for personalised information access. In: Teh adaptive web. Berlin Heidelberg: Springer, pp. 54-89.

Gentzkow, M. \& Shapiro, J. M., 2011. Ideological Segregation Online and Offline. The Quarterly Journal of Economics, 1 November, 126(4), pp. 1799-1839.

Gillmor, D., 2004. We the Media. The Rise of Citizen Journalists. National Civic Review, 93(3), pp. 58-63. 
Goldhaber, M. H., 1997. The Attention Economy: The Natural Economy of the Net. First Monday, pp. 113.

Gomez Marmol, F., Gil Perez, M. \& Martinez Perez, G., 2014. Reporting Offensive Content in Social Networks: Toward a Reputation-Based Assessment Approach. Internet Computing, IEEE, 2 18, pp. 32-40. Google, 2013. Google Transparancy Report, http://www.google.com/transparencyreport/: sn

Grimmelmann, J., 2010. Some skepticism about search neutrality. In: The Next Digital Decade: Essays on the Future of the Internet. Washington D.C.: TechFreedom, pp. 435-460.

Hain, K., 2006. Regulierung in den Zeiten der Konvergenz. Wirtschaftliche und und/oder medienrechtliche Steuerung?. $K \& R$, p. 325 subsq..

Hargittai, E., 2000. Open Portals or Closed Gates? Channeling Content on the World Wide Web. Poetics, pp. 233-253.

Hargittai, E., 2003. The Digital Divide and What to Do About It. In: New Economy Handbook. San Diego: Academic Press.

Hargittai, E., 2007. Content Diversity online: Myth or reality? . In: Media Diversity and Localism: Meaning and Metrics. Mahwah, NJ. : Lawrence Erlbaum, pp. 349-362.

Hasebrink, U. \& Schmidt, J.-H., 2013. Medienübergreifende Informationsrepertoires. Zur Rolle der Mediengattung und einzelner Angebote für Information und Meinungsbildung. Media Perspektiven, Issue 1, pp. 2-12.

Helberger, N., 2005. Controlling Access to Content. Regulating Conditional Access in Digital Television. Den Haag: Kluwer Law International.

Helberger, N., 2007-2008. Access denied: How some e-commerce businesses re-errect national borders for online consumers, and what European law has to say about this. European Journal of Consumer Law, pp. 472-506.

Helberger, N., 2012. Diversity by design. Journal of Information Policy, pp. 441-469.

Helberger, N., 2012. Exposure Diversity as a Policy Goal. Journal of Media Law, pp. 65-92.

High Level Expert Group on Media Freedom and Pluralism, 2013. A free and pluralistic media to sustain European democracy, Brussels: s.n.

Himelboim, I. \& McCreery, S., 2012. New technology, old practices: Examining news websites from a professional perspective. Convergence: The International Journal of Research into New Media Technologies, 1 November, 18(4), pp. 427-444. 
Himelboim, I., McCreery, S. \& Smith, M., 2013. Birds of a Feather Tweet Together: Integrating Network and Content Analyses to Examine Cross-Ideology Exposure on Twitter. Journal of Computer-Mediated Communication, 18(2), pp. 40-60.

Himelboim, I., Smith, M. \& Shneiderman, B., 2013. Tweeting apart: Applying network analysis to detect selective exposure clusters in Twitter. Communication Methods and Measures, 7(3-4), pp. 195-223.

Hindman, M., 2007. A mile wide and an inch deep: Measuring media diversity online and offline. In: Media Diversity and Localism: Meaning and Metrics. Mahwah: Lawrence Erlbaum, pp. 327-48.

Hindman, M. e., 2003. Googlearchy: How a few heavily-linked sites dominate politics on the web. Annual Meeting of the Midwest Political Sciences Association.

Hoppner, T., 2013. Google: Friend or Foe of Ad-Financed Content Providers?. Journal of Media Law, pp. 14-30.

ICRI, KU Leuven et.al. , 2009. Independent Study on Indicators for Media Pluralism; A monitoring tool for assessing risks for media pluralism in the EU Member States, Leuven: ICRI,KU Leuven -; MMTC, Jönköping International Business School -; CMCS, Central European University -; Ernst \& Young Consultancy.

Idate, I. T., 2008. User-Created-Content: Supporting a participative Information Society, Brussels: European Commission.

Irmen, A. \& Thisse, J.-F., 1998. Competition in Multi-characteristics Spaces. Journal of Economic Theory, 78(1), pp. 76-102.

Jouët, J., Vedel, T. \& Comby, J.-B., 2011. Political information and interpersonal conversations in a multimedia environment: A quantitative and qualitative examination of information practices in France. European Journal of Communication, 1 December, 26(4), pp. 361-375.

Ju, A., Jeong, S. H. \& Chyi, H. I., 2013. Will social media save newspapers?. Journalism Practice, 8(1), pp. 1-17.

Jullien, B., 2005. Two-Sided Markets and Electronic Intermediaries. CESinfo Economic Studies, pp. 235262.

Kalyanaraman, S. \& Sundar, S. S., 2006. he Psychological Appeal of Personalized Content in Web Portals: Does Customization Affect Attitudes and Behavior?. Journal of Communication, 56(1), pp. 110-132.

Karppinen, K., 2012. Rethinking media pluralism. New York: Fordham University Press.

Keane, M. T., O'Brien, M. \& Smyth, B., 2008. Are People Biased in Their Use of Search Engines?. Communications of the ACM, pp. 49-52.

Kommission zur Ermittlung der Konzentration im Medienbereich, 2010. Medienkonzentration und Sicherung der Meinungsvielfalt. [Online]. 
Kommission zur Ermittlung der Konzentration im Medienbereich, sd Online medien. [Online] Available at: http://www.kek-online.de/Inhalte/onlinemedien.html

Kreile, J. \& Thalhofer, T., 2014. Suchmaschinen und PLuralitätsanforderungen - Ist ohne gesetzliche Regelung der Suchmaschine der Pluralismus und die Meinungsvielfalt in Gefahr?. Zeitschrift für Urheber und Medienrecht, pp. 629-638.

Kuehling, J. \& Gauss, N., 2007. Suchmaschinen - eine Gefahr für den Informationszugang und die Informationsvielfalt?. ZUM, pp. 881-889.

Laidlaw, E. B., 2010. A framework for identifying Internet information gatekeepers. International Review of Law, Computers \& Technology, pp. 263-276.

Laidlaw, E. B., 2010. A framework for identifying Internet information gatekeepers. International Review of Law, Computers \& Technology, pp. 263-276.

Larsson, A. O., 2012. Understanding nonuse of interactivity in online newspapers: Insights from structuration theory. The Information Society, 28(4), pp. 253-263.

Lavie, T. et al., 2010. User attitudes towards news content personalization. International Journal of Human-Computer Studies, 68(8), pp. 483-495.

Lenhart, A. \& Fox, S., 2006. Bloggers: A portrait of the internet's new storytellers. Washington, DC: Pew Internet \& American Life Project.

Lessig, L., 2008. Remix: Making art and commerce thrive in the hybrid economy. New York, NY: Penguin.

Lewin, K., 1943. Forces behind food habits and methods of change. Bulletin of the National Research Council, pp. 35-65.

Machill, M. \& Beiler, M., 2009. The importance of the internet for journalistic research. A multi-method study of the research performed by journalists working for daily newspapers, radio, television and online. Journalism Studies, 10(2), pp. 178-203.

Marres, N. \& de Vries, G., 2002. Tussen toegang en kwaliteit. Legitimatie en contestatie van expertise op het Internet. In: De Publieke Dimensie van Kennis. WRR Voorstudies en Achtergronden. Den Haag: Sdu Uitgevers, pp. 171-247.

Marsden, C. \& Cowie, C., 1999. Convergence: Navigating Bottlenecks In Digital Pay-TV. Info: The Journal of Policy, Regulation and Strategy for Telecommunications, Information and Media.

McQuail, D., 1992. Media Performance, Mass Communication and the Public Interest. London: Sage Publishing.

Meier, W. \& Trappel, J., 2007. Medienkonzentration und Media Governance. In: Von der Mediepolitik zur Media Governance?. Koeln: Herbert von Halem Verlag, p. 197 subsq.. 
Milyo, J., 2007. The Effects of Cross-Ownership on the Local Content and Political Slant of Local Television News, Washington D.C.: FCC.

Motta, M. \& Polo, M., 2001. Beyond the Spectrum Constraint: Concentration and Entry in the Broadcasting Industry. Rivista di Politica Economia.

Mutz, D. C. \& Young, L., 2011. Communication and Public Opinion: Plus Ça Change?. Public Opinion Quarterly, 1 December, 75(5), pp. 1018-1044.

Napoli, P., 1999. Deconstructing the Diversity Principle. Journal of Communication, pp. 7-34.

Napoli, P., 2011. Exposure Diversity Reconsidered. Journal of Information Policy, p. 246-259.

Napoli, P., 2014. Digital intermediaries and the public interest standard in algorithm governance.

[Online]

Available at: http://blogs.Ise.ac.uk/mediapolicyproject/2014/11/07/digital-intermediaries-and-thepublic-interest-standard-in-algorithm-governance/

[Geopend March 2015].

Napoli, P. \& Karppinen, K., 2013. Translating diversity to internet governance. First Monday, pp. 1-17.

Neuberger, C. \& Lobgis, F., 2010. Die Bedeutung des Internets im Rahmen der Vielfaltssicherung. Berlin: Vistas.

Neuberger, C., Nuernbergk, C. \& Rischke, M., 2009. "Googleisierung" oder neue Quellen im Netz?. In: Journalismus im Internet. sl:VS Verlag für Sozialwissenschaften, pp. 295-334.

Newman, N., 2009. The rise of social media and its impact on mainstream journalism. Oxford: Reuters Institute for the Study of Journalism.

Newman, N., 2011. Mainstream media and the distribution of news in the age of social discovery. Oxford: Reuters Institute for the Study of Journalism.

Nielsen, R. K. \& Schrøder, K. C., 2014. The relative importance of social media for accessing, finding, and engaging with news. Digital Journalism, pp. 1-18.

Ofcom, 2010. Report on public interest test on the proposed acquisition of British Sky Broadcasting Group plc by News Corporation, London: Ofcom.

Ofcom, 2012. Report on measuring media plurality, London: Ofcom.

Olmstead, K., Mitchell, A. \& Rosenstiel, T., 2011. Navigating news online: Where people go, how they get there and what lures them away. Pew Research Center.

Örnebring, H., 2008. The consumer as producer - of what? User-generated tabloid content in The Sun (UK) and Aftonbladet (Sweden). Journalism Studies, Oktober, 9(5), pp. 771-785. 
Östman, J., 2012. Information, expression, participation: How involvement in user- generated content relates to democratic engagement among young people. New Media \& Society, 1 September, 14(6), pp. 1004-1021.

Owen, B., 2009. Old Media Policy Failures, New Policy Changes. SIEPR Discussion Paper No. 08-38.

Paal, B. P., 2012. Suchmaschinen, Marktmacht und Meinungsbildung, sl: Commissioned by Initiative for a Competitive Online Marketplace.

Pan, B. et al., 2007. In Google We Trust: Users' Decisions on Rank, Position, and Relevance. In Google We Trust: Users' Decisions on Rank, Position, and Relevance, pp. 801-823.

Pantti, M. \& Bakker, P., 2009. Misfortunes, memories and sunsets: Non-professional images in Dutch news media. International Journal of Cultural Studies, 1 September, 12(5), pp. 471-489.

Papacharissi, Z., 2009. Audiences as Media Producers: Content Analysis of 260 Blogs. In: Blogging, Citizenship, and the Future of Media. New York, NY: Routledge, pp. 21-38.

Papacharissi, Z. \& de Fatima Oliveira, M., 2012. Affective News and Networked Publics: The Rhythms of News Storytelling on \#Egypt. Journal of Communication, 62(2), pp. 266-282.

Pariser, E., 2011. The Filter Bubble: What the Internet is Hiding From You. London: Viking.

Pollock, R., 2010. Is Google the Next Microsoft: Competition, Welfare and Regulation in Online Search. Review of Network Economics, pp. 1-29.

Polo, M., 2007. Regulation for pluralism in media markets. In: The Economic Regulation of Broadcasting Markets. Cambridge: Cambridge University Press.

Robertson, S. P., Vatrapu, R. K. \& Medina, R., 2009. The social life of social networks: Facebook linkage patterns in the 2008 U.S. presidential election. The Proceedings of the 10th International Digital Government Research Conference, pp. 6-15.

Roehle, T., 2010. Der Google Complex. Ueber Macht im Zeitalter des Internets. Berlin: Transcript Verlag. Schaeferkordt, A., 2009. Sechs Fagen zur Reform des Medienkonzentrationsrechts. In: Fesseln fuer die Vielfalt? Medienkonzentrationsrecht auf dem Pruefstand. Hamburg: C.F. Mueller, pp. 65-78.

Schoenbach, K., 2007. The Own in the Foreign: Reliable Surprise - An Important Function of the Media. Media, Culture \& Society, pp. 344-353.

Schulz, W., Dreyer, S. \& Hagemeier, S., 2011. Machtverschiebung in der oeffentlichen Kommunikation. Bonn: Friedrich Ebert Stiftung.

Schulz, W., Held, T. \& Kops, M., 2002. Perspektiven der Gewährleistung freier öffentlicher. Baden-Baden: Nomos. 
Schulz, W., Held, T. \& Laudien, A., 2005. Search Engines as Gatekeepers of Public Communication: Analysis of the German framework applicable to internet search engines including media law and anti trust law. German Law Journal, pp. 1419-1433.

Shoemaker, P. J., 2009. Gatekeeping Theory. New York: Routledge.

Singer, J. B. et al., 2011. Participatory journalism. Guarding open gates at online newspapers. Chichester: Wiley-Blackwell.

Springer, N. \& Wolling, J., 2008. Recherchoogeln. Wie Zeitungsjournalisten das Internet für ihre Arbeit nutzen. In: Journalismus online - Partizipation oder Profession?. sl:VS Verlag für Sozialwissenschaften, pp. 45-59.

Stark, B., 2009. Digitale Programmnavigation. Media Perspektiven, pp. 233-246.

Stark, B., Magin, M. \& Jürgens, P., 2014. Navigieren im Netz. Befunde einer qualitativen und quantitativen Nutzerbefragung. In: Die "Googleisierung" der Informationssuche. Suchmaschinen zwischen Nutzung und Regulierung. Berlin: de Gruyter, pp. 20-73.

Sunstein, C., 2007. Republic.com 2.0. Princeton: Princeton University Press.

Tambini, D., 2011. Reforming Consumer Representation in the UK Communications, London: LSE Media Policy Project: Media policy brief 4.

Tambini, D., 2013. New parameters for a plurality regulation on the internet. sl:sn

Tarlach, M., 2011. Minority Rights, Freedom of Expression and of the Media: Dynamics and Dilemmas. Cambrudge: Intersentia.

Taylor, G., 2013. Search Quality and Revenue Cannibalization by Competing Search Engines. Journal of Economics \& Management Strategy, 22(3), pp. 445-467.

Themelis, A. T., 2013. Information and Intermediation, Abuse of Dominance and Internet 'Neutrality': 'Updating' Competition Policy under the Digital Single Market and the Google Investigations ?. European Journal of Law and Technology.

Thurman, N., 2007. The globalization of journalism online: A transatlantic study of news websites and their international readers. Journalism, pp. 285-307.

Thurman, N., 2011. Making 'The Daily Me': Technology, economics and habit in the mainstream assimilation of personalized news. Journalism, pp. 395-415.

Thurman, N. \& Schifferes, S., 2012. The future of personalization at news websites. Journalism Studies, pp. $775-790$. 
Trammell, K. D., Tarkowski, A., Hofmokl, J. \& Sapp, A. M., 2006. Rzeczpospolita blogów [Republic of Blog]: Examining Polish Bloggers Through Content Analysis. Journal of Computer-Mediated Communication, 11(3), pp. 702-722.

Tremayne, M., Zheng, N., Lee, J. K. \& Jeong, J., 2006. Issue publics on the web: Applying network theory to the war blogosphere. Journal of Computer-Mediated Communication, 12(1), pp. 290-310.

Trilling, D., 2013. Following the news: patterns of online and offline news consumption.. Amsterdam: ASCoR.

Valcke, P., 2004. Digitale Diversiteit - Convergentie van Media-, Telecommunicatie- en Mededingingsrecht. Brussel: Larcier.

Valcke, P., 2011. Looking for the user in media pluralism: Unraveling the traditional diversity chain and recent trends of user empowerment in European media regulation. Journal of Information Policy, pp. 287-320.

Van Couvering, E., 2007. Is Relevance Relevant? Market, Science, and War: Discourses of Search Engine Quality. Journal of Computer-Mediated Communication, pp. 866-887.

Van Damme, K., Courtois, C., Verbrugge, K. \& De Marez, L., 2015. What's APPening to news? A mixedmethod audience-centred study on mobile news consumption. Mobile Media \& Communication, 2 3, pp. 196-213.

Van der Sloot, B., 2012. Walking a Thin Line: The Regulation of EPGs. Jipitec, pp. 138-147.

Van der Wurff, R., 2004. Program Choices of Multichannel Broadcasters and Diversity of Program. Journal of Broadcasting \& Electronic Media, pp. 135-150.

Van Dijk, J., 2012. Facebook and the engineering of connectivity: a multi-layered approach to social media platforms. Convergence: The International Journal of Research into new Media Technologies, pp. 1-15.

Van Eijk, N. A., 2009. Search Engines, the New Bottleneck for Content Access. In: TELECOMMUNICATION MARKETS, DRIVERS AND IMPEDIMENTS. sl:Springer, pp. 141-157.

Van Eijk, N. A., 2011. About Network Neutrality 1.0, 2.0, 3.0 and 4.0. Computers \& Law Magazine, pp. 14.

Van Hoboken, J., 2012. Search Engine Freedom. On the implications fo the Right to Freedom of Expression for the legal Governance of Web Search Engines. Den Haag: Kluwer Law International.

Varian, H., 2008. Official Blog. [Online]

Available at: http://googleblog.blogspot.ch/2008/02/our-secret-sauce.html

[Geopend 19 January 2014].

Vonbun, R. \& Schönbach, K., 2014. Wer ist politisch aktiv im Social Web?. Publizistik, pp. 1-14. 
Watanabe, K., 2013. The western perspective in Yahoo! News and Google News: Quantitative analysis of geographic coverage of online news. International Communication Gazette, pp. 141-156.

Webster, J. G. \& Ksiazek, T. B., 2012. The dynamics of audience fragmentation: Public attention in an age of digital media. Journal of Communication, 62(1), pp. 39-56.

Webster, J. G. \& Phalen, P. F., 1994. Victim, consumer or Commodity? Audience Models in Communications Policy. In: Audience making: How the Media Create the Audience. sl:Sage, pp. 19-37.

Westlund, O., 2013. Mobile news. A review and model of journalism in an age of mobile media. Digital journalism, 1 1, pp. 6-26.

White, A., 2013. Search Engines: Left Side Quality versus Right Side Prof. International Journal of Industrial Organization, 22 April, Volume 31, pp. 690-701.

White, D. M., 1950. The "Gate Keeper": A Case Study in the Selection of News. Jounalism Quarterly, pp. 383-390.

Zarsky, T. Z., 2003. "MINE YOUR OWN BUSINESS!": MAKING THE CASE FOR THE IMPLICATIONS OF THE DATA MINING OF PERSONAL INFORMATION IN THE FORUM OF PUBLIC OPINION. Yale Journal of LaW \& Technology, pp. 1-55. 